\title{
Article \\ A Flexible Future Education Model-Strategies Drawn from Teaching during the COVID-19 Pandemic
}

\author{
Seshasai Srinivasan ${ }^{1, *}$, Juan Antonio Lopez $\operatorname{Ramos}^{2}$ and Nasim Muhammad ${ }^{3}$ \\ 1 W Booth School of Engineering Practice and Technology, McMaster University, \\ Hamilton, ON L8S4L8, Canada \\ 2 Department of Mathematics, Universidad de Almería, 04120 Almería, Spain; jlopez@ual.es \\ 3 Department of Mathematics and Statistics, School of Engineering Technology, Mohawk College, \\ Hamilton, ON L9C0E5, Canada; nasim.muhammad@mohawkcollege.ca \\ * Correspondence: ssriniv@mcmaster.ca
}

check for updates

Citation: Srinivasan, S.; Ramos, J.A.L.; Muhammad, N. A Flexible Future Education Model-Strategies Drawn from Teaching during the COVID-19 Pandemic. Educ. Sci. 2021, 11, 557. https://doi.org/10.3390/ educsci11090557

Academic Editor: Eleanor Dommett

Received: 18 August 2021

Accepted: 14 September 2021

Published: 17 September 2021

Publisher's Note: MDPI stays neutral with regard to jurisdictional claims in published maps and institutional affiliations.

Copyright: (C) 2021 by the authors. Licensee MDPI, Basel, Switzerland. This article is an open access article distributed under the terms and conditions of the Creative Commons Attribution (CC BY) license (https:/ / creativecommons.org/licenses/by/ $4.0 /)$.

\begin{abstract}
As they emerge from the pandemic, universities worldwide are evaluating the adaptations in the education sector during the pandemic and determining their course of action for the future. In this work, drawing on the lessons from four courses across two different universities, a survey of over 300 students, and the literature, we present strategies for successfully implementing a flexible blended education format. The survey revealed that the performance of the cohort taking the course during the pandemic performed nearly the same as the cohorts that took the courses before the pandemic. However, the students did not prefer an entirely virtual format, felt that their social wellbeing was impacted, and preferred a hybrid education model with a lot of supplementary learning material. As a key contribution of this work, we have identified and elaborate on four key pillars for a flexible blended education format, namely, course design, pedagogical strategies incorporating active learning and providing a sense of online community, infrastructure for delivery and training, and incorporating activities that support student wellbeing.
\end{abstract}

Keywords: future learning; COVID-19 lessons; blended learning; online learning; strategies

\section{Introduction}

In December 2019, patients with pneumonia-like symptoms were admitted to the hospitals in Wuhan, China. In no time, this spread to other provinces, and the health authorities initiated investigations. Within the first few weeks of 2020, the existence of the Novel Coronavirus was confirmed. As this spread to other countries, a worldwide pandemic was declared. The pandemic not only had, and continues to have, a devastating effect on human lives but also forced many businesses to shut down.

Educational institutions were not insulated from the impact of the pandemic. In the initial weeks of the pandemic, many institutions were completely shut down and were forced to reinvent themselves to continue the educational activities. Instructors worldwide had to adopt digital technologies to deliver their courses in a virtual environment [1]. Several of them were not conversant with the new technologies and modern strategies for virtual education [2]. Lack of infrastructure, financial and technical resources and logistic challenges were also prominent in several cases. There are numerous articles on the impact of COVID-19 on teaching and learning [2-15].

Despite the above, universities around the world showed resilience and adapted to the new reality by choosing to offer their educational programs in an online/virtual format. This was needed because an abrupt shutdown with uncertainty on the end date of the pandemic, and thereby the opening of the university, could disrupt the graduation cycles of millions of students around the world, significantly impacting their future. However, with this new evolution in education, there is now a wider gap in educational inequality because of a strong reliance on technology [2,16]. A total of 1.6 billion students have been 
affected by this pandemic. In the western part of the world, due to the digital divide, the most impacted communities include people of African origin, Hispanic, and indigenous communities. A recent report by Dorn et al. [17] has highlighted that the pandemic has left the students from the vulnerable sections of society with the most undesirable learning environments that are severely deficient in resources and support systems. This is echoed by [16], who have found that in the Netherlands, which had a very short lockdown period, has equitable school funding, and has high levels of internet penetration, students made little or no progress while learning from home.

Further, the authors noted that the learning loss was glaring among the students from the disadvantaged sections of society. Among the less educated households, the learning slide was approximately $60 \%$ higher than the general population [16]. Needless to say, to prevent a domino effect that will marginalize the less fortunate students even more in the post-pandemic world due to a pandemic-forced lag in preparations, the public, private, and social sectors must collaborate to invest and innovate the education space. This is critical to bring excellence and equity into the education system that is currently failing too many students.

The other major consequence of the shutdown is the impact on the overall wellbeing of many students at the lower levels of the socio-economic strata and who rely on the schools for the nutritional and, in some cases, health and educational needs [10]. Numerous investigations have focused on the wellness and health issues due to the pandemic-forced lockdown [18-21]. Students are showing wellness issues due to the increased stress and lack of social and peer-to-peer interactions [10]. These studies highlight that schools are not only to provide education to the students but also present an environment of social interaction and a forum to collaborate and share ideas and experiences. Though a virtual environment provides opportunities for peer-to-peer interactions, they are not as effective as the physical space offered by the in-person learning environment where the students can develop social competencies. In other words, social and emotional learning is largely diminished in the virtual environment, leading to an overall reduction in the wellbeing of the students.

Despite the above challenges in online education, there is a significant investment being made by universities to offer online courses [22]. Apart from flexibility, this can be attributed to the immense market opportunity online education provides, namely, working professionals who can pursue an up-gradation of their credentials. Besides, an online environment means students from any geographical region could join the classroom, widening the student enrollment. With a reduction in operational expenses and ease of creating and offering content of reasonable quality, there is potential to significantly increase revenues. With the academic adjustments made during the pandemic and the lessons learned in virtual classrooms and online courses, it is anticipated that this mode of education is likely to make significant inroads into the formal education system [23-25]. Acknowledging that the experience gained from pandemic will have a strong influence on the future of education and knowledge from our own experience that there is a solid preference for embracing hybrid and blended learning environments in the future, the objective of this research is to define the strategies to successfully move in this direction. For this, we begin by presenting a summary of our findings from four different courses across two different universities, i.e., one course from a Spanish university and three courses from a Canadian university. Specifically, we present the details of the evolution of a virtual classroom for three courses during the pandemic, outlining the best practices adopted during the pandemic. We present a quantitative measure of the student learning via the assessment during the covid pandemic. We compare the students' performance with the previous cohorts to draw conclusions on the impact of the virtual model of education. We also evaluated the opinion of over 300 students who were surveyed on the online format of education. Finally, considering all of this, we present the challenges and strategies moving forward in a post-pandemic environment. In particular, armed with these findings, we 
present the key points that one must consider for a blended or virtual learning environment in a post-pandemic setting.

\section{Materials and Methods}

\subsection{Course Design}

As mentioned earlier, three of the courses are taught at McMaster University in Canada, and one course is taught in Universidad de Almería in Spain. Of the three courses taught at McMaster University, the first course is a second-year subject focused on the topics relating to signals and systems (Course-A). The course is taught from the mathematics perspective and is focused on the properties of continuous and discrete signals and systems, Fourier series and Fourier transform, and Laplace-transform. The second course is taught to the first-year students and is focused on object-oriented programming (Course-B). The specific topics taught in the course include pointers, data structures, classes, inheritance, and polymorphism. The third course is on Finite element analysis (FEA), taught to the third-year students at McMaster University's Automotive and Vehicle Engineering Technology program (Course-C). This course focuses on: (i) the foundational concepts, including the solution approaches and verification processes, to apply FEA techniques to solve engineering design problems. (ii) structural analysis of trusses, beams, and frames, and (iii) thermal analysis. Finally, the fourth course (Course-D), offered by Universidad de Almería, is a general mathematics course taught to first-year students in Computer Sciences. The course covers algebraic concepts in Discrete Mathematics and Linear Algebra. Specifically, the topics include arithmetic on finite fields and polynomials, graphs, Boolean functions, vectors spaces, and linear functions.

The number of students registered in the four courses before and during the pandemic is summarized in Table 1. Courses taught at McMaster University spanned 13 weeks. In Course-A and Course-B, each week, the student met with the instructor for a total duration of $4 \mathrm{~h}$ (split into two 2-h classes). While the first 2-h class focused on delivering the content and teaching the principles, the second session was used for hands-on training in which students would apply the concepts to solve various problems. In Course-C, the class met once every week for a 3-h duration. In this course, in each class, as in the other courses, the students learned the concepts and were trained to apply the concepts to solve real engineering problems. All three courses at McMaster University were offered to the undergraduate engineering students at the W Booth School of Engineering Practice and Technology. Course-D taught at Universidad de Almería spanned 15 weeks with the class meeting $4 \mathrm{~h}$ each week. Three hours each week were used for instruction in which the concepts were delivered, along with some examples that demonstrated the application of the concepts. The students were also given some problems to solve during these three-hour sessions. The fourth hour was used as a tutorial session in which students worked with their peers and the instructor to solve the problems they were unable to solve earlier. Thus, the tutorial session helped elucidate the concepts for the students.

Table 1. The enrollment in the pandemic and non-pandemic cohorts for each course.

\begin{tabular}{ccc}
\hline Course & Non-Pandemic Cohort & Pandemic Cohort \\
\hline Course-A & 73 & 154 \\
Course-B & 94 & 89 \\
Course-C & 66 & 76 \\
Course-D & 181 & 204 \\
\hline
\end{tabular}

\subsection{Procedure}

The entire learning environment across all the courses was based on the constructivist learning theory [26-30]. In this, students were asked to solve different kinds of problems that would require applying concepts. Further, they were encouraged to discuss the solution approaches with their peers, during and outside the class. While they were encouraged to develop designs and solutions collaboratively, they had to submit individual 
reports/assignments/labs as part of their assessment. The exposure to different problems, variety of solution approaches, and an enriching environment where they can interact with others to learn their approach and views helps students develop a robust mental construction of the principles.

\section{The Adaptation for the Pandemic}

During the pandemic, the courses were offered in a fully online format. All classes at McMaster University were offered via zoom, whereas in Universidad de Almería, the classes were offered via Blackboard Collaborate Ultra. A key challenge was to ensure attendance and active participation from the students. This became an even stiffer challenge when we adopted the practice of providing lecture notes before the classes and making the video recordings of the lectures available to the students through the university's learning management system. These measures were encouraged by the university administration to ensure that students who face technical difficulties during the class or who cannot join the regular class since they are in a different time zone will be able to learn without any significant hindrance. Further, there are students with special accommodations who might not be able to manage their learning at the pace of the virtual class and would rely on the materials available before and after the class.

Therefore, to teach these courses, various pedagogical options were considered for the virtual learning environment. These include problem-based learning [29,31-36], projectbased learning [37], active learning [38-45], research-based learning [46-48], inquiry-based learning [49], problem solving based approach [50], co-operative and small group learning $[38,40]$. From these, an active learning environment was preferred because it enables students to learn in a hands-on mode. In particular, employing a constructivist theory of learning $[26,27,29,51]$, students engaged in problem-solving sessions engaging with peers and the instructor that encourage them to reflect on their understanding of the concepts and their applications, generating a greater contextual understanding of the course content. Classroom participation and engaging in problem-solving sessions would be a very enriching educational experience for the students, something that will not be completely achieved by simply reading the class notes or watching the lecture videos. Therefore, the course material provided before the start of the class through the university's learning management system was not complete. More precisely, some of the slides only contained the problem description without complete solutions. During the classroom sessions, students were required to engage with peers and the instructor to determine the solution to the problems. We found this to be a reasonable strategy to encourage students to attend classes, and we had significant attendance levels (>85\%) in all the courses.

Virtual assessments were conducted to measure student learning. In this, to minimize collaboration, we did the following in all the courses: A database of questions was generated in the university's learning management system. Each student was given a random set of questions to be solved within a specific time. Thus, we were able to generate several versions of the tests. Further, depending upon the course, the students were required to either submit a scanned version of the solutions to an online dropbox or enter their answers within the textboxes provided in the online exam form. This exercise had to be completed within a stipulated time. Finally, in Courses-A and B, which were delivered in Winter 2021, the assessments during the pandemic were done in a proctored environment in which the students took the exams while being proctored via a camera. On the other hand, due to the absence of a formal university policy, this was not possible in Course-C that was delivered in Fall 2020. In Course-D, the assessments were done online. However, the assessments were not proctored due to the lack of staff personnel to invigilate the exams. Nevertheless, the instructors were online during the exam to answer student questions. We believe that this combination of random questions and a stringent timeline to solve the problems minimized the chances of collaboration during the exam. A student would prefer to solve his/her exam first before helping someone else. Further, with a strict timeline, it 
will be unlikely that a student would be able to complete his/her exam, submit it, and then assist someone else.

\section{Results from Our Courses}

The performance of the students in different courses is shown in Figure 1a-d. To better understand the education and learning experience of the students, in each figure, we also include a comparison with an equivalent cohort that took the same courses in a non-pandemic setting. It must be emphasized that both cohorts appeared for the same type of assessments with the same difficulty levels. The only difference is that before the pandemic, the assessments for these courses were held in person.
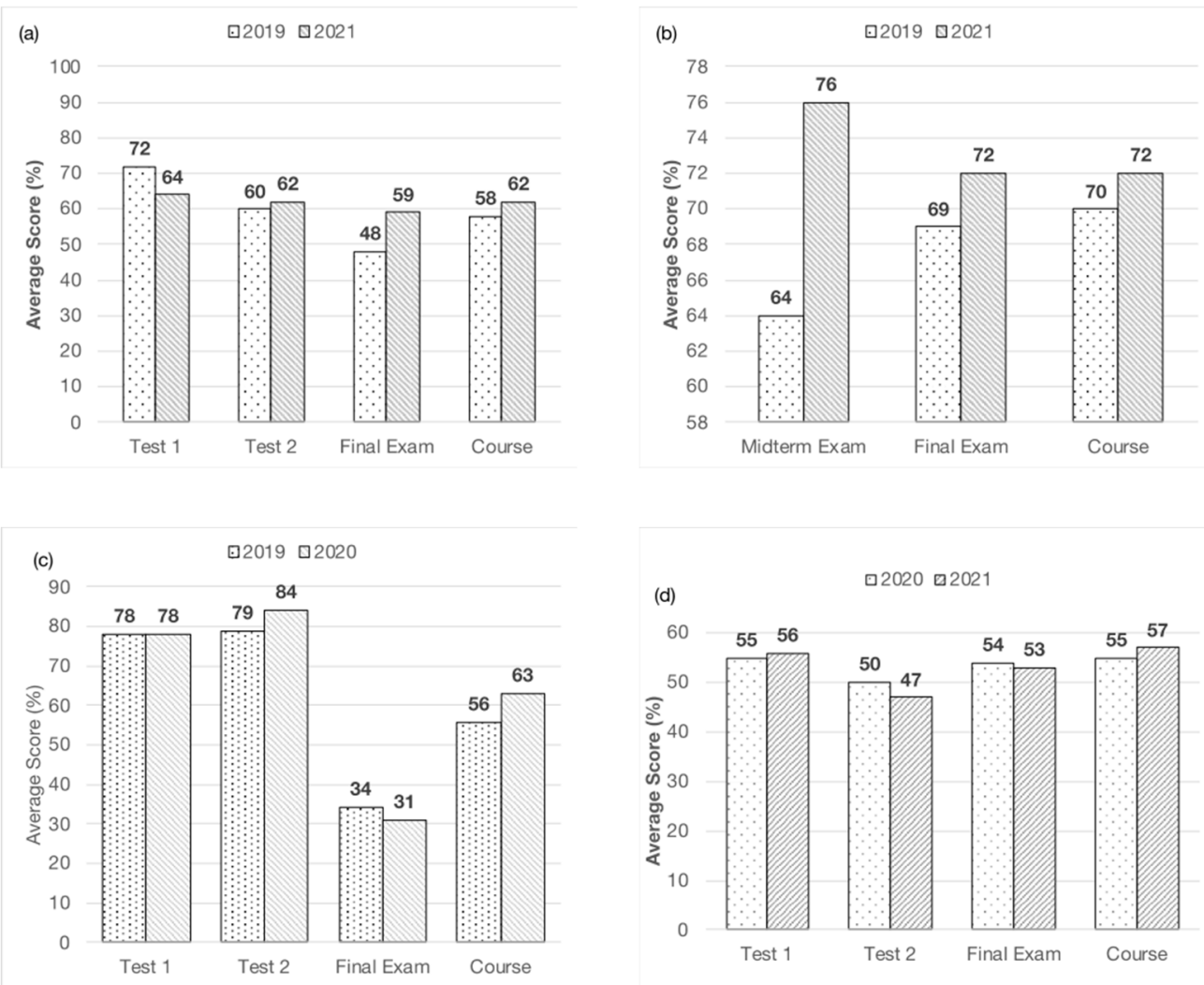

Figure 1. Performance of the students in (a) Course-A (b) Course-B (c) Course-C and (d) Course-D over different assessments. The cohorts in 2019 took the assessments in person, whereas the cohorts in 2020 and 2021 took similar assessments in a virtual format.

As seen in these figures, the students' performance in most of the assessments is almost similar in the pandemic and non-pandemic cohorts. The outliers are Test- 1 and Final exam in Course-A, Midterm exam in Course-B, and Test-2 in Course-C. For example, from the final course grades in all the courses, we see that the difference between the two cohorts in Courses-A and B are statistically insignificant and can be attributed to variation in the population. In Course-C, the students' performance during the pandemic is nearly $7 \%$ better. However, this can be attributed to the strong performance in Test-2. It must be noted that this test was invigilated on camera, and as such, we did not notice any anomalies in the results. In Course-A, the students in the pandemic cohort did relatively poorly in Test-1. It could be argued that since they were made aware of the performance of the previous cohorts in the corresponding assessments, they began to work better towards the subsequent assessments, significantly improving their performance in the final exam. The performance of the non-pandemic cohort continuously decreased, perhaps since students invest their time optimally to perform well in all the courses they take during the term. In fact, we can explain the fluctuations in the student scores through the term via this 
explanation. This is consistent with the propositions of [52]. In Course-D, the results are very close in the two cohorts (pandemic and non-pandemic). However, a remarkable achievement during the pandemic at the Universidad de Almería is the sharp decline in the number of students who withdraw from the course. More precisely, in the non-pandemic cohort, nearly $41 \%$ exercised this option and left the course without appearing for the final exam, avoiding a grade on the transcript. On the other hand, during the pandemic, the dropout rate was just $11 \%$. This drastic improvement could be attributed to the inclusion of several supporting activities such as quizzes, problem-solving sessions, assignments, etc., within the course. While these activities were designed as support mechanisms for students during the pandemic, the students utilized them to engage with the subject continuously for the entire duration of the term, eventually being better prepared for the final exam.

\subsection{Student Opinion}

In general, from the students' performance in the assessments, one could argue that online education did not significantly impact student learning and that the transition was without any major issues. However, such a conclusion could be farfetched because it does not include the voice of the key stakeholders, i.e., students. Therefore, to complete the analysis, we conducted a detailed survey of the students in these courses. The survey was aimed at understanding the student experience and preferences towards online learning. The specific questions that were posted to the students are summarized in Appendix A.

While the survey was administered at McMaster University for 292 students, a total of 200 completed surveys were received. Sixteen incomplete surveys were discarded from the analysis of the survey. In Universidad de Almería, this survey was administered to 204 students, but only 106 completed it. The results from the survey can be categorized into two major categories: 1 . Lecture and supplementary videos-usage and preferences 2. Virtual learning—-student experience and impact on students.

\subsubsection{Lecture and Supplementary Videos}

As seen in Figure 2, an overwhelming fraction of the students preferred to have supplementary videos to learn the material well and are confident that it will help them improve their understanding of the material (Q1 in Appendix A). Most of the students felt they would prefer to look for supplementary videos on the learning management system if it is available (Q2, Q3 in Appendix A). Further, nearly 50\% of the students at McMaster University and over $75 \%$ of the students at Universidad de Almería claimed that if a video recording of the lecture is available, then they would focus more on learning the material instead of ensuring that the notes are recorded appropriately (Q4, Figure 3$)$.

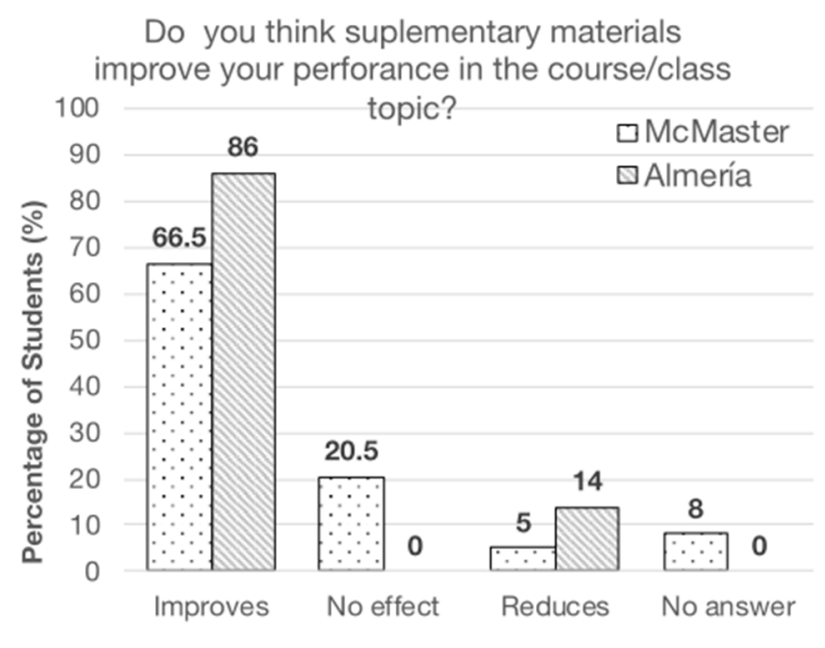

Figure 2. Student response on whether supplementary material helps them learn the concepts better. 


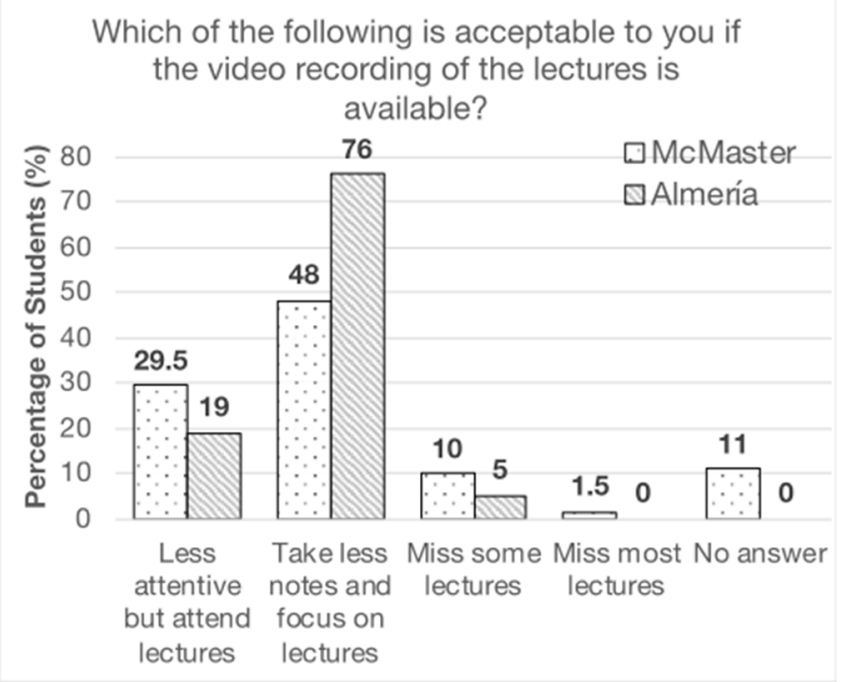

Figure 3. Student opinion on their approach to lectures if video recording of the lectures is available.

When probed about their likelihood to miss classes if the materials are provided online, students acknowledged that they might consider missing classes if the lecture videos are available (Q5 in Appendix A, c.f. Figure 4a). However, they stated that the availability of lecture videos would not be a major factor influencing their decision on missing classes (Q6 in Appendix A, c.f. Figure 4b).
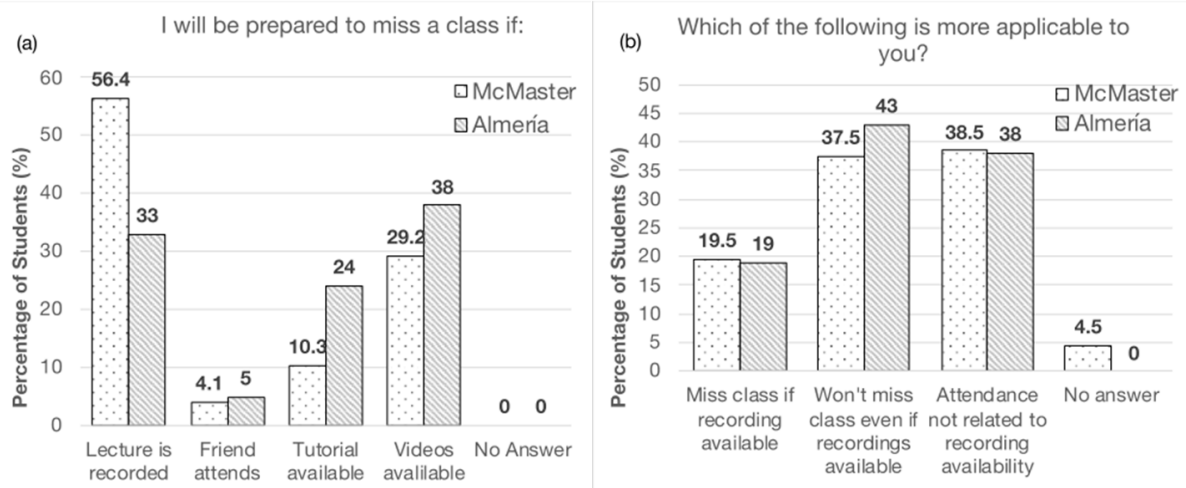

Figure 4. Student response on (a) the circumstances under which they would prefer to miss a lecture, and (b) how they perceive the availability of the lecture recordings might impact their attendance.

Finally, with respect to the length of the supplementary videos, we found that the students preferred short videos (5 min or 15-20 min) instead of watching a $60 \mathrm{~min}$ or more extended video recording (Q7, Q8 in Appendix A). In fact, the students are unlikely to view very long videos (60 min or longer) $(\mathrm{Q} 9$ in Appendix $A)$.

\subsubsection{Online Learning Environment}

As seen in Figure 5a, most students were not comfortable with fully online learning (Q10 in Appendix A). Further, the students felt that online learning somewhat hindered their learning, and so they preferred in-person learning (Q11 in Appendix A, c.f. Figure 5b). This is despite the fact that the students' performance across the different courses was nearly the same when we compare the final course grades of the pandemic cohorts with the non-pandemic cohorts (c.f. Figure 1). This is not surprising because the students who took the courses in the online environment were abruptly thrown into it and were completely cut off from a university ambiance that provides an enriching environment to socialize with peers and opportunities to explore the discipline interacting with the peers and instructors. 
This, coupled with the pandemic challenges impacting their personal lives, adds to the negative impression about online education.
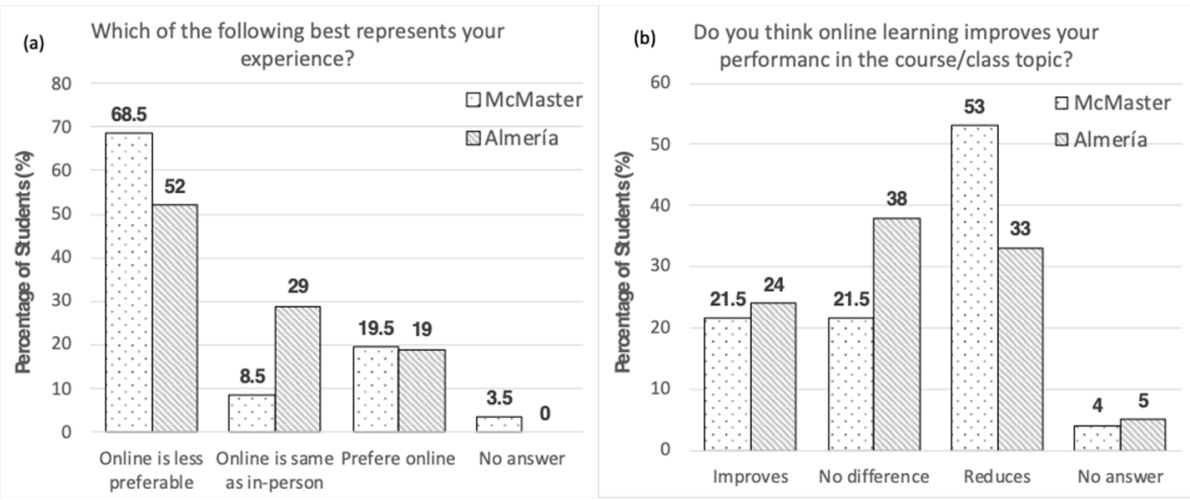

Figure 5. Student response on (a) their preference for online versus in-person learning and (b) how online learning has impacted their learning.

In fact, as seen in Figure 6, reinforcing the above, an overwhelming number of students indicated that online learning harmed their wellbeing (Q12 in Appendix A). Further, in response to ancillary questions about the online format of education, nearly $70 \%$ of the students at McMaster University and well over $50 \%$ of students at Universidad de Almería yearned for face-to-face interaction with peers and instructors (Q13, Q14 in Appendix A), and felt that their social wellbeing significantly declined. The technical issues they faced with online classes during the pandemic emanating from many reasons, such as poor internet connectivity, data, bandwidth, technological incompetence, etc., further added to their frustration with online learning (Q15 in Appendix A). Almost half the students surveyed at McMaster University reported encountering occasional technical difficulty, $28 \%$ reported some difficulty, and about $10 \%$ reported extreme difficulty.

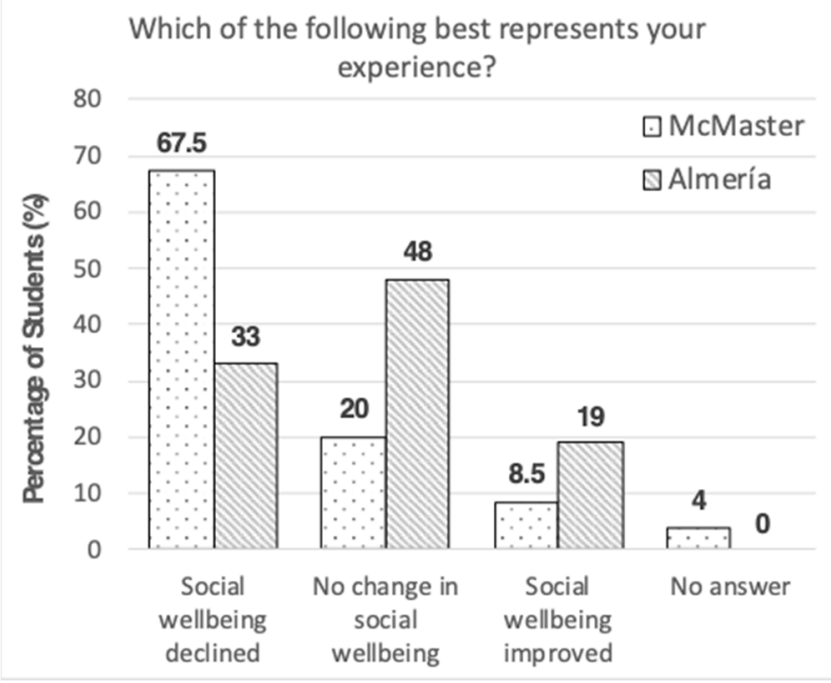

Figure 6. Student response on their social wellbeing because of the forced online education format.

However, despite the above negative feedback on online learning and a preference for in-person classes, when given a choice, nearly $41 \%$ of the surveyed students at McMaster University and $57 \%$ of the surveyed students at Universidad de Almería preferred to have a hybrid offering of courses (Q16 in Appendix A, Figure 7). This is due to the flexibility with the hybrid approach in which the students would have an opportunity to engage with their peers in person and at the same time periodically exercise the option of attending 
the classes from home. This, in conjunction with the availability of supplementary videos, online lectures, and course materials, is appealing to them as an ideal learning environment. We believe that a significant fraction of the students ( $46 \%$ at McMaster University and $29 \%$ at Universidad de Almería) who prefer an on-campus format of education are the ones who have had a very negative experience in a fully online format of education. We believe that if the hybrid model of education is established correctly, many of the students in this category will prefer the hybrid model.

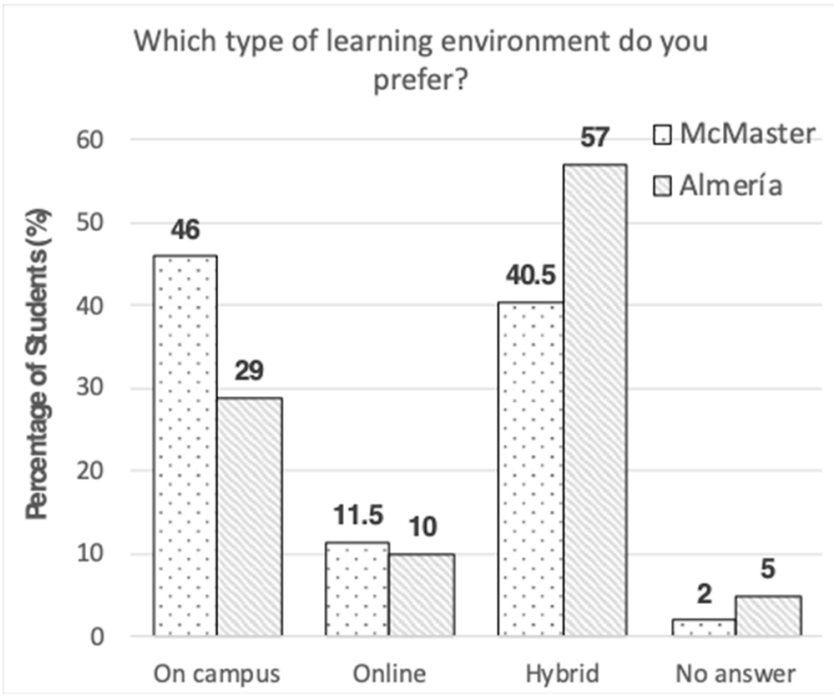

Figure 7. Student preference on the format of education for the future.

\subsection{Challenges with Online Education}

With all the above results and after going through the four courses during the pandemic, we identified several potential issues that can impact the quality of online education: (i) Attendance could be impacted if the materials are already provided to the students via the university's learning management system. There must be mechanisms in the form of mandatory attendance and in-class activities that require student participation to encourage attendance. (ii) The traditional closed-book closed-notes assessments in an online format will likely be inefficient in an online setting and are mired with challenges. While the availability of resources for online proctoring will help, this is still likely to be outpaced by emerging technologies that will make access to information and the exchange of knowledge easy for the students. (iii) Social wellbeing will be impacted in the absence of that university environment that allows students to interact with their peers and instructors to enrich their learning experience. (iv) Technical issues such as poor internet connectivity and other technical glitches will continue to remain in the future. Even if they are temporary, these disruptions can negatively impact the quality of education. (v) If courses that require laboratory experiments are offered through virtual labs, the graduates will have very poor hands-on experience and thereby deficient levels of laboratory skills.

\section{Discussion and Cues for the Future}

Universities worldwide adjusted their modes of education to deliver the courses curing the pandemic $[8,14,15,53]$. It is also evident that remote learning will likely improve with time, and institutions worldwide will be better prepared in the next few years [54]. However, it must be noted that just technological advancement and adequate internet penetration are not enough to provide an excellent virtual education to the students. The results from the assessments in multiple courses of this work (c.f. Figure 1) point to this. This is also verified in the case study by Engzell et al. [16], who analyzed the student performance in the Netherlands that was technologically well prepared for the pandemic, had very short school closures and has equitable-school funding programs. In the ensuing 
paragraphs, we provide our commentary on the points to be considered for delivering a high-quality education experience for the students. For this, we have identified the key pillars of quality education as (i) a well-designed course content, (ii) novel pedagogical strategies incorporating active learning techniques to engage students in the class and create a sense of online community, (iii) better infrastructure for delivery and training, and (iv) incorporating practices that promote student wellness and health.

\subsection{Course Design and Delivery}

In our opinion, going forward, it would be optimal to use a combination of in-person and virtual education, i.e., a hybrid format. This is inferred from the survey wherein the students want a blended/hybrid environment (c.f. Figure 7). A hybrid model of education in which some courses or parts of courses are taught in-person and some in a virtual mode will introduce flexibility in learning for the students, allow them to interact with peers when they are on campus for certain aspects of the course, help universities optimize their resources, especially if they are operating on budget and space constraints. Specifically, courses that are primarily theoretical and that require discussions and reading could be offered in a virtual format, perhaps with a few in-person contact sessions for students to engage and interact with peers. Courses that are primarily hands-on in nature that require students to perform experiments and engage in activities to experience the concepts, for example, PLC programming, design techniques in Civil engineering, etc., could be primarily held in an in-person environment. Our views are in agreement with other proponents of hybrid learning, such as in Refs. $[23,55,56]$, who claim that with an appropriate framework that resolves the key challenges of flexibility, an active learning environment for interaction, and effective pedagogy, this mode of education will be very popular and make education accessible even to working professionals who can upgrade their education.

In addition to novel curriculum design approaches [57], as pointed out by other researchers, flexible learning should include the following: a variety of learning modes, offering students the choice on the pace, content, and the sequence in which they learn the content, and location-independence [58-61]. Having said this, it must also be kept in mind that students might not be skilled at self-direction and self-regulation that is essential to be successful in such highly flexible educational environments $[62,63]$. In scheduling classes, the timing of the class also matters since depending upon the subject, the students performance can be impacted by the time of the day the class is held [64]. Further, virtual delivery should be planned more carefully because we are also faced with technological and attendance issues in addition to the above challenges associated with it. Keeping in mind the digital divide pointed out by Engzell et al. [16] and Carroll and Conboy [2], while embracing technology, we must be mindful of the vulnerable sections that might not be able to access live lectures or might face technical issues during live lectures. To ensure an equitable learning opportunity for all students, it would be appropriate to maintain flexibility by taking measures such as making reading material, lecture material, and recordings of lectures available and accessible to the students [56].

Supplementary course materials such as short videos of key concepts and examples in which the concepts are applied to solve problems, etc., significantly boost the quality of education for the students. This has been identified as very helpful by a vast majority of the students who participated in the survey in this study. Additionally, from our survey, it is clear that students seem to prefer having access to any multimedia material relating to the topics covered in the classes. In traditional learning methodology, students are advised on readings and explained what will be learned in the following lessons. However, students do not usually pursue the recommended printed material before joining the classroom with a higher level of understanding of the concepts covered in those classes unless there is a grade component associated with such pre-class work. On the other hand, it seems students would be inclined to review short multimedia components before or after class to prepare themselves better for a high-stakes assessment. 


\subsection{Active Learning Pedagogy}

We must also be mindful that providing all these materials might tempt the students to miss classes. Knowing that the quality of education would be greatly impacted when students choose to use only supplementary content and lecture videos instead of attending the lectures live and interacting with peers and the instructor, appropriate measures to encourage attendance are necessary. One way of doing this is by providing lecture materials with some missing components. For example, solutions to all sample questions need not be provided in the lecture slides. Students could be encouraged to work with their peers and the instructor to obtain solutions to problems. In other words, the instructor should use active learning strategies, and incorporate activities during the class time to bolster attendance, perhaps even mandating attendance. However, it must be remembered that due to technical difficulties, students might be missing classes. Also, there might be students who have special accommodations needing additional time to complete the class activity.

To ensure active student participation in in-person and online activities, it might be an excellent strategy to start the courses with an in-person session wherein students can introduce themselves to their peers and familiarize themselves with the learning environment in which they will participate. Such an introductory meeting will significantly benefit the students in forming study groups, stimulate interactions, helping students create the social life of the school. This could be followed by routine opportunities for the students to interact with their peers in an online environment, helping them understand the essence of the disciplines through various perspectives shared by their peers. In summary, integrating principles and practices of active learning pedagogy as prescribed by several researchers in the literature can boost the quality of education [38-45].

\subsection{Infrastructure and Training}

Having adequate digital infrastructure resources is critical for the successful delivery of a course either in an online format or blended format. Infrastructure is critical for the following activities: course delivery, content creation, content sharing, training instructors. For example, in an abrupt transition to a virtual model of learning, several instructors were unfamiliar with the digital technology to deliver content. They had to create course materials since, prior to the pandemic, they were not using technology to deliver the content. Many of them did not have a good understanding of the novel pedagogical approaches that need to be adapted to engage the classroom in a virtual setting. This also necessitates appropriate teacher training programs that help improve the techno-pedagogy skills of the instructors $[65,66]$.

\subsection{Assessments}

In the courses discussed here, strategies that enable creating a unique assessment with a strict deadline for each student were used to mitigate student collaboration during assessments. However, despite this, since on-camera invigilation was not pursued, it opens a window of opportunity for students to collaborate. Currently, the evolved university policy at McMaster allows for monitoring students live on camera during the exams. Further, we have also been exercising this option in other courses to ensure no collaboration happens for assessments designed for a closed-book closed-notes format.

While pursuing this approach for assessments is an option, going forward, we must reconsider this approach to assessments. Instructors should adopt more novel assessments approaches [67-70]. For example, interviews of students to understand their comprehension of the various topics, focus group transcripts, portfolios, and open-book exams that focus on the upper levels of Bloom's taxonomy [71] and challenge-based learning that would require students to undertake projects that employ the concepts and principles taught in the course. These assessments allow the instructor to evaluate the students ability to apply the concepts, thereby validating their fundamental knowledge on the subject. However, it is essential to recognize that with large classes, the implementation is 
probably not easy. Spanjers et al. [68] found that quizzes are a very effective way to track student progress and measure their learning in an online environment. Personal response systems such as clickers are effective tools for group quizzes and discussion prompts [72]. Collaborative group projects will encourage deep discussions, driving a constructivist form of learning. Self-assessment tools should also be provided for the students in the form of ungraded quizzes, web-based learning and evaluation tools to help students gauge where they stand [73]. While these are some effective tools to assess the learning, it must be kept in mind that the timeliness of feedback is equally critical. Quick feedback will prevent a wrong concept from taking deep roots in the minds of the students. In other words, it is easier to rectify the concepts in the students' minds as soon as they have learned them instead of trying to mend their incorrect understanding that has been cemented in their minds for a long time $[39,41,42]$.

\subsection{Student Wellbeing}

Student wellness should be an essential aspect of our education process. We must employ strategies and coordination to ensure that student wellbeing is kept in mind while undergoing rigorous curriculum training. For example, to mitigate the stress levels, an instructor could consider avoiding high-stakes assessments and instead distribute the weights over several low stakes assessments. This will not only ensure that the students are constantly engaged throughout the term and being periodically assessed in smaller chunks but will avoid critical situations wherein a single high-stakes assessment will determine whether they pass or fail the course. Such high-stress assessments could drive students to desperation and nudge them to pursue undesirable routes to pass the assessment.

Other sources of stress are related to the technology itself. It could be due to poor internet connectivity during a lecture, submitting assessments, or completing tests and exams. This can be mitigated by allowing for some flexibility in assessment submission policies and uploading recordings of lecture videos. Besides this, supporting the students with peer tutoring sessions is also a mechanism to help them learn the material at their own pace.

Social wellbeing is essential for students to succeed in their education. In a hybrid learning environment, the interaction with peers and the instructor can play a very positive role. In fact, the psycho-social relationship is a critical aspect of hybrid learning design $[60,74,75]$. These interactions can help assuage students overcome the sense of isolation [76], help them learn better in a constructivist environment [59]. The interactions should not only focus on curriculum content allowing students to undertake group study activities but should also promote a positive learning environment that allows for emotional engagement to keep the students motivated, confident, and enthusiastic about learning $[58,77,78]$. For instance, to motivate students, one could introduce interactive online activities such as games, puzzles, quizzes, and flash exercises based on topics that were covered earlier. Apart from this, the instructor can pose thought-provoking questions that need group problem-solving skills or introduce problem-based learning. To ensure a seamless connection between the in-person and online classes, there must be a clear plan to conveniently transit between the two phases to ensure that the students do not lose enthusiasm for the subject.

\section{Limitations of This Study and Scope for Future Work}

The findings of this research emanate from four courses across two different countries with a population of slightly over 300 students. These specific courses are selected since they are taught by the authors across two successive formats, namely, during the pandemic and before the pandemic. Since the courses only cover mathematics and computer science topics, the key findings cannot be generalized across all engineering disciplines. Further, it is important to note that while we have used formative assessments inside the classroom to calibrate the in-class activities and help students understand their shortcomings and improve their understanding of the concepts, these are not explicitly quantified and analyzed. 
We believe that these formative assessments helped the instructor enhance the quality of education, and the students were able to learn the concepts better, ultimately helping them perform well in the summative assessments. Put differently, the formative assessments effectiveness and impact are indirectly captured in the summative assessments. The other points that we have not considered in this study, and which are likely to have contributed to the outcome of the survey and student preference, include the following:

(i) The students from level-1 and level-3 have been surveyed. However, there is a difference in the maturity levels of these students, with the latter being more selfaware and more entrenched in the university culture. The impact of these parameters has not been accounted for in the evaluations.

(ii) While we have surveyed students from two countries in different courses and drawn our conclusions based on the surveys and test results, the impact of parameters such as cultural differences, societal contexts, national contexts, etc., have not been considered.

(iii) The operationalization of tasks and assessments across four different courses are not identical, and the variations and effects due to these variations have not been factored in our analysis.

(iv) Further, in comparing the cohorts before and during the pandemic, the impacts on student performance due to the variation in the population and the mental state of the students due to the pandemic have not been considered.

Future research could be focused on a more exhaustive study involving courses from different disciplines, involving a much larger population, and account for the additional parameters listed above. In particular, because this sample population prefers a hybrid model of education, it would be important to undertake investigations that probe this preference further, offer effective course design and offering strategies, and study the effects of hybrid mode of education on student learning.

\section{Summary and Conclusions}

In this work, we present education strategies that can be adopted in the post-pandemic scenario. In arriving at this strategy, we evaluate our experience in four different courses across two universities. We compare the outcomes during the pandemic with the results when these courses were offered before the pandemic. We also surveyed over 300 students across the two universities to gather their opinion on (i) their education experience during the pandemic, (ii) and their preferences on the course offering. The key highlights of our findings from these include the following:

(i) The cohorts that took the course during the pandemic in a virtual setting had almost the same overall course grade as the cohorts that took the course before the pandemic in an in-person setting.

(ii) Students who took the survey before the final course grades were revealed felt that their learning diminished during the pandemic and did not like the fully virtual model of education.

(iii) Students preferred to have supplementary material such as course notes, short supplementary videos that explain the concepts, and the lecture recordings. They felt that these immensely helped them in better understanding the concepts.

(iv) The social wellbeing of the student was greatly impacted, with a large fraction of the students claiming that it either declined (Canadian students) or remained unchanged (Spanish students).

(v) In a post-pandemic scenario, a large bulk of students preferred a hybrid model of education that will give them the flexibility for on-campus as well as virtual education.

From the results of this work and the findings in the literature, we establish that an impactful change is imminent in the post-pandemic education processes. Specifically, a hybrid model of education is likely to be embraced by many educational institutions. From our adaptation in the pandemic courses, the outcomes in these courses, and the student 
opinion, we identified four key pillars for a successful implementation of a course in a hybrid or fully virtual format:

(i) A well-designed course that offers flexibility in the pace of learning, variety of learning modes, location independence, and offers the students a choice on pace, content, and to some extent, the sequence in which they learn the content, thereby providing equitable learning opportunities for all students.

(ii) Novel pedagogical strategies that incorporate active learning techniques to engage students in the class and create a sense of online community. Provide adequate supplementary materials to foster self-paced learning. Use a variety of assessment techniques that focus on upper levels of Bloom's taxonomy and rapid in-class assessment techniques that focus on the lower levels of Bloom's taxonomy.

(iii) Infrastructure for delivery and training for the following activities: course delivery, content creation, content sharing, and training instructors on techno-pedagogy competencies.

(iv) Student wellbeing is a critical aspect of hybrid and fully virtual learning design. Create a vibrant virtual learning community that aims to bring the campus social life into the virtual setting by incorporating activities that promote peer interactions and provide opportunities for emotional engagement to keep the students motivated, confident, and enthusiastic about learning.

In summary, given the reality of universities embracing the hybrid or fully virtual mode of education in at least some parts of the curriculum, this paper has outlined the strategic steps one could take to position themselves to successfully deliver a course in a hybrid or fully virtual setting.

Author Contributions: S.S., J.A.L.R. and N.M. contributed equally to the conceptualization, investigation, data collection, and analysis. S.S. was involved in writing the major portions of the initial draft of the manuscript. All authors contributed equally to review and edit the manuscript. All authors have read and agreed to the published version of the manuscript.

Funding: This research received no external funding.

Institutional Review Board Statement: The study was conducted according to the guidelines of the Declaration of Helsinki, and approved by the Research Ethics Board at McMaster University (MREB \# 5145 and 24 November 2020). At Universidad de Almería the university officials determined that the ethics clearance is not applicable for this study since no personal information is collected from the students at Universidad de Almería.

Informed Consent Statement: Informed consent was obtained from all subjects from McMaster University and Universidad de Almería that were involved in the study as part of the survey protocol, and we are allowed to publish this paper.

Data Availability Statement: All the survey data are reported in the Appendix A.

Acknowledgments: The authors are grateful to the reviewers for investing their time in evaluating this manuscript and providing constructive suggestions to improve the manuscript.

Conflicts of Interest: The authors declare no conflict of interest.

\section{Appendix A}

The following are the list of questions and the options that were asked during the survey. Besides each option two numbers are provided. These represent the percentage of respondents who chose that option from Universidad de Almería and McMaster University, respectively.

\section{Survey Questions}

1. Do you think supplementary materials improve your performance in the course/ class/topic?

Supplementary videos/recorded lectures improve my performance. $(85.71,66.5)$ 
Supplementary videos/recorded lectures are no different than in person learning for my performance. $(0,20.5)$

Supplementary videos/recorded lectures reduce my performance $(14.29,5.0)$

No answer $(0,8.0)$

2. For a given course, how likely are you to watch all videos and attend all lectures?

Extremely likely $(19,18.5)$

Somewhat likely $(43,45.5)$

Somewhat unlikely $(38,23.5)$

Extremely unlikely $(0,9)$

No answer $(0,3.5)$

3. If you had access to pre-recorded videos, how likely are you to watch these before attending class?

Extremely likely $(0,11.5)$

Somewhat likely $(42.36,37.5)$

Somewhat unlikely $(37.9,29.5)$

Extremely unlikely $(19.1,19)$

No answer $(0,2.5)$

4. Which of the following is acceptable to you if the video recording of the lecture is available?

Be a little less attentive in classroom but attend most lectures $(33,29.5)$

Take less notes in the classroom but attend most lectures $(5,48)$

Miss more lectures, but still attend some $(24,10)$

Miss the lectures $(38,1.5)$

Extremely unlikely

No answer $(0,11)$

5. Please rank the options in the order that is most appropriate for you, where 1 is most likely and 4 is least likely.

I will be prepared to miss a class if:

The lecture is recorded $(33,56.4)$

My friend is attending the lecture instead and can explain it to me $(4.8,4.1)$

A tutorial session is available $(23.7,10.3)$

Short 5 min videos are available for learning the concepts $(38,29.2)$

No answer $(0.5,0)$

6. Which of the following is more applicable to you?

- I would miss more lectures if the lectures are recorded and available online $(19,19.5)$

I would not miss a lecture even if the recorded lectures are available online $(76,37.5)$

My attendance is not dependent upon the availability of lecture recording $(5,38.5)$

No answer $(0,4.5)$

7. Which of the following are you likely to watch if you are having trouble with a certain topic?

5 min video specifically on the topic- $(86,54)$

$60 \mathrm{~min}$ lecture video in which the concept is explained for 5-10 min- $(0,34)$

$120 \mathrm{~min}$ lecture video in which the concept is explained for $5-10 \mathrm{~min}-(14,8.5)$

No answer- $(0,3.5)$

8. What video length do you prefer to watch for a certain topic?

A concept with examples explained using a package of $5-7$ min videos- $(9.5,24.5)$

A concept with examples explained in one 15-20 min video- $(76.2,51)$

Full 60-120 min lecture video consisting of multiple concepts with examples- $(14.3,22.5)$

No answer- $(0,2.0)$ 
9. Please indicate your top reason for NOT watching a video:

It is too long- $(52,49)$

It is of no interest- $(14.28,8.0)$

I learn better with peers- $(4.76,7.5)$

I do not have time- $(19.04,21.0)$

There is no grade incentive- $-(9.52,4.5)$

No answer- $(0,10.0)$

10. Which of the following best represents your experience?

Online learning is less preferable than in-person learning $(52,68.5)$

Online learning is no different than in-person learning $(29,8.5)$

I prefer online learning to in-person learning $(19,19.5)$

No answer $(0,3.5)$

11. Do you think online learning improves your performance in the course/class/topic?

Online learning improves my performance $(33,21.5)$

Online learning is no different than in person learning for my performance $(48,21.5)$

Online learning reduces my performance $(19,53)$

No answer $(0,4)$

12. Which of the following best represents your experience?

My social wellbeing has declined as a result of online learning $(24,67.5)$

My social wellbeing has not changed as a result of online learning $(38,20)$

My social wellbeing has improved as a result of online learning $(33,8.5)$

No answer $(5,4)$

13. In the online learning environment, how is lack of face-to-face peer interaction affecting you?

I am extremely negatively affected $(9.52,22)$

I am somewhat negatively affected $(47.31,46.5)$

I am somewhat positively affected $(0,7)$

I am extremely positively affected $(0,4)$

I am not at all affected $(42.55,18.5)$

No answer $(0,2)$

14. How is lack of face-to-face instructor interaction affecting you:

I am extremely negatively affected $(14.28,21)$

I am somewhat negatively affected $(38,49.5)$

I am somewhat positively affected $(4.76,5)$

I am extremely positively affected $(0,4)$

I am not at all affected $(42.35,17)$

No answer $(0,3.5)$

15. Have you had or do you have issues with internet connectivity, data, bandwidth, or other technology that impacts your ability to attend online courses and/or access course content?

Yes, extreme difficulty $(-, 10)$

Yes, some difficulty $(-, 28)$

Occasional difficulty $(-, 44.5)$

No difficulty $(-, 15)$

No answer $(-, 2.5)$

16. What type of learning environment do you prefer?

Campus environment $(29,46)$

Work from home $(10,11.5)$

A hybrid approach with both in-person and work from home options $(57,40.5)$ 
No answer $(5,2)$

\section{References}

1. Bao, W. COVID-19 and online teaching in higher education: A case study of Peking University. Hum. Behav. Emerg. Technol. 2020, 2, 113-115. [CrossRef]

2. Carroll, N.; Conboy, K. Normalising the "new normal": Changing tech-driven work practices under pandemic time pressure. Int. J. Inf. Manag. 2020, 55, 102186. [CrossRef]

3. Aguilera-Hermida, P.A. College students' use and acceptance of emergency online learning due to COVID-19. Int. J. Educ. Res. Open 2020, 1, 100011. [CrossRef]

4. Nash, C. Report on Digital Literacy in Academic Meetings during the 2020 COVID-19 Lockdown. Challenges 2020, 11, 20. [CrossRef]

5. Pokhrel, S.; Chhetri, R. A Literature Review on Impact of COVID-19 Pandemic on Teaching and Learning. High. Educ. Futur. 2021, 8, 133-141. [CrossRef]

6. Pozo, J.-I.; Pérez Echeverría, M.-P.; Cabellos, B.; Sánchez, D.L. Teaching and Learning in Times of COVID-19: Uses of Digital Technologies During School Lockdowns. Front. Psychol. 2021, 12, 1511. [CrossRef] [PubMed]

7. Zhang, W.; Wang, Y.; Yang, L.; Wang, C. Suspending Classes Without Stopping Learning: China's Education Emergency Management Policy in the COVID-19 Outbreak. J. Risk Financ. Manag. 2020, 13, 55. [CrossRef]

8. Bojović, Ž.; Bojović, P.D.; Vujošević, D.; Šuh, J. Education in times of crisis: Rapid transition to distance learning. Comput. Appl. Eng. Educ. 2020, 28, 1467-1489. [CrossRef]

9. Chatterjee, I.; Chakraborty, P. Use of Information Communication Technology by Medical Educators Amid COVID-19 Pandemic and Beyond. J. Educ. Technol. Syst. 2020, 49, 310-324. [CrossRef]

10. Colao, A.; Piscitelli, P.; Pulimeno, M.; Colazzo, S.; Miani, A.; Giannini, S. Rethinking the role of the school after COVID-19. Lancet Public Health 2020, 5, 370. [CrossRef]

11. Dhawan, S. Online Learning: A Panacea in the Time of COVID-19 Crisis. J. Educ. Technol. Syst. 2020, 49, 5-22. [CrossRef]

12. Mishra, L.; Gupta, T.; Shree, A. Online teaching-learning in higher education during lockdown period of COVID-19 pandemic. Int. J. Educ. Res. Open 2020, 1, 100012. [CrossRef]

13. Mok, K.H.; Xiong, W.; Ke, G.; Cheung, J.O.W. Impact of COVID-19 pandemic on international higher education and student mobility: Student perspectives from mainland China and Hong Kong. Int. J. Educ. Res. 2021, 105, 101718. [CrossRef]

14. Muhammad, N.; Srinivasan, S. Online Education During a Pandemic-Adaptation and Impact on Student Learning. Int. J. Eng. Pedagog. 2021, 11, 71-83. [CrossRef]

15. Muhammad, N.; Srinivasan, S. Transition from In-Class to Online Lectures during a Pandemic BT-Visions and Concepts for Education 4.0; Auer, M.E., Centea, D., Eds.; Springer International Publishing: Cham, Switzerland, 2021; pp. 307-314.

16. Engzell, P.; Frey, A.; Verhagen, M.D. Learning loss due to school closures during the COVID-19 pandemic. Proc. Natl. Acad. Sci. USA 2021, 118, e2022376118. [CrossRef] [PubMed]

17. Dorn, E.; Hancock, B.; Sarakatsannis, J.; Viruleg, E. COVID-19 and Learning Loss-Disparities Grow and Students Need Help; McKinsey \& Company: Chicago, IL, USA, 2020; pp. 1-13.

18. Savage, M.J.; James, R.; Magistro, D.; Donaldson, J.; Healy, L.C.; Nevill, M.; Hennis, P.J. Mental health and movement behaviour during the COVID-19 pandemic in UK university students: Prospective cohort study. Ment. Health Phys. Act. 2020, $19,100357$. [CrossRef]

19. Essadek, A.; Rabeyron, T. Mental health of French students during the Covid-19 pandemic. J. Affect. Disord. 2020, 277, 392-393. [CrossRef]

20. Kaparounaki, C.K.; Patsali, M.E.; Mousa, D.-P.V.; Papadopoulou, E.V.K.; Papadopoulou, K.K.K.; Fountoulakis, K.N. University students' mental health amidst the COVID-19 quarantine in Greece. Psychiatry Res. 2020, 290, 113111. [CrossRef] [PubMed]

21. Copeland, W.E.; McGinnis, E.; Bai, Y.; Adams, Z.; Nardone, H.; Devadanam, V.; Rettew, J.; Hudziak, J.J. Impact of COVID-19 Pandemic on College Student Mental Health and Wellness. J. Am. Acad. Child Adolesc. Psychiatry 2021, 60, 134-141. [CrossRef] [PubMed]

22. Sun, A.; Chen, X. Online Education and Its Effective Practice: A Research Review. J. Inf. Technol. Educ. Res. 2016, 16, 157-190. [CrossRef]

23. Ashour, S.; El-Refae, G.A.; Zaitoun, E.A. Post-pandemic Higher Education: Perspectives from University Leaders and Educational Experts in the United Arab Emirates. High. Educ. Futur. 2021, 8, 219-238. [CrossRef]

24. Teichler, U. The future of higher education and the future of higher education research. Tert. Educ. Manag. 2003, 9, 171-185. [CrossRef]

25. Zhao, Y. COVID-19 as a catalyst for educational change. Prospects 2020, 49, 29-33. [CrossRef]

26. Jonassen, D.H. Thinking Technology: Toward a Constructivist Design Model. Educ. Technol. 1994, 34, 34-37.

27. Srinivasan, S.; Muhammad, N. A Constructivist Approach for Mathematics Education. J. Educ. Pedagog. 2020, 12, 1-5.

28. Hunter, A.-B.; Laursen, S.L.; Seymour, E. Becoming a scientist: The role of undergraduate research in students' cognitive, personal, and professional development. Sci. Educ. 2007, 91, 36-74. [CrossRef]

29. Srinivasan, S.; Centea, D. Problem Based Learning in Finite Element Analysis BT-Visions and Concepts for Education 4.0; Auer, M.E., Centea, D., Eds.; Springer International Publishing: Cham, Switzerland, 2021; pp. 240-246. 
30. Srinivasan, S.; Muhammad, N. Implementation of a Course in Computational Modeling of Biological Systems in an Undergraduate Engineering Program. Int. J. Eng. Educ. 2020, 36, 857-864.

31. Gijbels, D.; Dochy, F.; Van den Bossche, P.; Segers, M. Effects of Problem-Based Learning: A Meta-Analysis From the Angle of Assessment. Rev. Educ. Res. 2005, 75, 27-61. [CrossRef]

32. Dochy, F.; Segers, M.; Van den Bossche, P.; Gijbels, D. Effects of problem-based learning: A meta-analysis. Learn. Instr. 2003, 13, 533-568. [CrossRef]

33. Centea, D.; Srinivasan, S. Assessment in problem-based learning using mobile technologies. In Advances in Intelligent Systems and Computing; Auer, M., Tsiatsos, T., Eds.; Springer: Cham, Switzerland, 2019; pp. 337-346.

34. Centea, D.; Srinivasan, S. A Comprehensive Assessment Strategy for a PBL Environment. Int. J. Innov. Res. Educ. Sci. 2016, 3, 364-372.

35. Sidhu, G.; Srinivasan, S.; Centea, D. Implementation of a Problem Based Learning Environment for First Year Engineering Mathematics. In Social Progress and Sustainability; Guerra, A., Rodriguez, F.J., Kolmos, A., Reyes, I.P., Eds.; Aalborg University Press: Aalborg, Denmark, 2017; pp. 201-208.

36. Centea, D.; Srinivasan, S. Enhancing Student Learning through Problem Based Learning. In PBL, Social Progress and Sustainability; Guerra, A., Rodriguez, F.J., Kolmos, A., Reyes, I.P., Eds.; Aalborg University Press: Aalborg, Denmark, 2017 ; pp. 376-385.

37. Guo, P.; Saab, N.; Post, L.S.; Admiraal, W. A review of project-based learning in higher education: Student outcomes and measures. Int. J. Educ. Res. 2020, 102, 101586. [CrossRef]

38. Wage, K.E.; Buck, J.R.; Wright, C.H.G.; Welch, T.B. The signals and systems concept inventory. IEEE Trans. Educ. 2005, 48, 448-461. [CrossRef]

39. Sidhu, G.; Srinivasan, S. An Intervention-Based Active-Learning Strategy To Enhance Student Performance in Mathematics. Int. J. Pedagog. Teach. Educ. 2018, 2, 277-288. [CrossRef]

40. Buck, J.R.; Wage, K.E. Active and cooperative learning in signal processing courses. IEEE Signal Process. Mag. 2005, $22,76-81$. [CrossRef]

41. Srinivasan, S.; Centea, D. An Active Learning Strategy for Programming Courses. In Mobile Technologies and Applications for the Internet of Things, Proceedings of the Mobile Technologies and Applications for the Internet of Things. Advances in Intelligent Systems and Computing; Auer, M., Tsiatsos, T., Eds.; Springer Nature: Berlin/Heidelberg, Germany, 2019; pp. 327-336.

42. Srinivasan, S.; Centea, D. Applicability of Principles of Cognitive Science in Active Learning Pedagogies. In Proceedings of the 13th International Workshop Active Learning in Engineering, Donostia, Spain, 6-10 July 2015; pp. 99-104.

43. Prince, M. Does Active Learning Work? A Review of the Research. J. Eng. Educ. 2004, 93, 223-231. [CrossRef]

44. Beichner, R. The Student-Centered Activities for Large Enrollment Undergraduate Programs (SCALE-UP) Project. Res. Based Reform Univ. Phys. 2007, 1, 2-39.

45. Cummings, K.; Marx, J.; Ronald, T.; Dennis, K. Evaluating innovation in studio physics. Am. J. Phys. 1999, 67, S38-S44. [CrossRef]

46. Bogoslowski, S.; Geng, F.; Gao, Z.; Rajabzadeh, A.R.; Srinivasan, S. Integrated Thinking-A Cross-Disciplinary Project-Based Engineering Education BT-Visions and Concepts for Education 4.0; Auer, M.E., Centea, D., Eds.; Springer International Publishing: Cham, Switzerland, 2021; pp. 260-267.

47. Deslauriers, L.; Schelew, E.; Wieman, C. Improved Learning in a Large-Enrollment Physics Class. Science 2011, 332, 862-864. [CrossRef]

48. Srinivasan, S.; Rajabzadeh, A.R.; Centea, D. A Project-Centric Learning Strategy in Biotechnology BT-The Impact of the 4th Industrial Revolution on Engineering Education; Auer, M.E., Hortsch, H., Sethakul, P., Eds.; Springer International Publishing: Cham, Switzerland, 2020; pp. 830-838.

49. Lewis, S.E.; Lewis, J.E. Departing from Lectures: An Evaluation of a Peer-Led Guided Inquiry Alternative. J. Chem. Educ. 2005, 82, 135. [CrossRef]

50. Muhammad, N.; Srinivasan, S. A Problem Solving Based Approach to Learn Engineering Mathematics BT-The Impact of the 4th Industrial Revolution on Engineering Education; Auer, M.E., Hortsch, H., Sethakul, P., Eds.; Springer International Publishing: Cham, Switzerland, 2020; pp. 839-848.

51. Dunham, T.; Wells, J.; White, K. Biotechnology Education: A Multiple Instructional Strategies Approach. J. Tech. Edu. 2002, 14, 65-81. [CrossRef]

52. Love, D.A.; Kotchen, M.J. Grades, Course Evaluations, and Academic Incentives. East. Econ. J. 2010, 36, 151-163. [CrossRef]

53. Radu, M.-C.; Schnakovszky, C.; Herghelegiu, E.; Ciubotariu, V.-A.; Cristea, I. The Impact of the COVID-19 Pandemic on the Quality of Educational Process: A Student Survey. Int. J. Environ. Res. Public Health 2020, 17, 7770. [CrossRef]

54. Montacute, R.; Cullinane, C. Learning in Lockdown; The Sutton Group: London, UK, 2021.

55. Bell, B.S.; Federman, J.E. E-Learning in Postsecondary Education. Futur. Child. 2013, 23, 165-185. [CrossRef]

56. Boelens, R.; De Wever, B.; Voet, M. Four key challenges to the design of blended learning: A systematic literature review. Educ. Res. Rev. 2017, 22, 1-18. [CrossRef]

57. Centea, D.; Srinivasan, S.; Singh, I.; Wanyama, T. A Collaborative Approach in Designing Curriculum for Industry 4.0 Software Integration Implementation BT-The Impact of the 4th Industrial Revolution on Engineering Education; Auer, M.E., Hortsch, H., Sethakul, P., Eds.; Springer International Publishing: Cham, Switzerland, 2020; pp. 135-144.

58. Chen, Y.; Wang, Y.; Kinshuk; Chen, N.-S. Is FLIP enough? Or should we use the FLIPPED model instead? Comput. Educ. 2014, 79, 16-27. [CrossRef] 
59. Owston, R.; York, D.; Murtha, S. Student perceptions and achievement in a university blended learning strategic initiative. Internet High. Educ. 2013, 18, 38-46. [CrossRef]

60. Ozkan, S.; Koseler, R. Multi-dimensional students' evaluation of e-learning systems in the higher education context: An empirical investigation. Comput. Educ. 2009, 53, 1285-1296. [CrossRef]

61. Ruiz, J.G.; Mintzer, M.J.; Leipzig, R.M. The Impact of E-Learning in Medical Education. Acad. Med. 2006, 81, 207-212. [CrossRef]

62. Barnard, L.; Lan, W.Y.; To, Y.M.; Paton, V.O.; Lai, S.-L. Measuring self-regulation in online and blended learning environments. Internet High. Educ. 2009, 12, 1-6. [CrossRef]

63. Van Laer, S.; Elen, J. In search of attributes that support self-regulation in blended learning environments. Educ. Inf. Technol. 2017, 22, 1395-1454. [CrossRef]

64. Muhammad, N.; Sidhu, G.; Srinivasan, S. Effect of the Time of Day of Instruction on Student Learning. Int. J. Pedagog. Teach. Educ. 2020, 4, 126-137.

65. Donitsa-Schmidt, S.; Ramot, R. Opportunities and challenges: Teacher education in Israel in the Covid-19 pandemic. J. Educ. Teach. 2020, 46, 586-595. [CrossRef]

66. Moralista, R.; Oducado, R.M. Faculty Perception toward Online Education in a State College in the Philippines during the Coronavirus Disease 19 (COVID-19) Pandemic. Univers. J. Educ. Res. 2020, 8, 4736-4742. [CrossRef]

67. Koc, S.; Liu, X.; Wachira, P. Assessment in Online and Blended Learning Environments; Information Age Publishing Inc.: Charlotte, NC, USA, 2015; ISBN 978-68123-045-0.

68. Spanjers, I.A.E.; Könings, K.D.; Leppink, J.; Verstegen, D.M.L.; de Jong, N.; Czabanowska, K.; van Merriënboer, J.J.G. The promised land of blended learning: Quizzes as a moderator. Educ. Res. Rev. 2015, 15, 59-74. [CrossRef]

69. Sidhu, G.; Srinivasan, S.; Muhammad, N. Challenge-Based and Competency-Based Assessments in an Undergraduate Programming Course. Int. J. Emerg. Technol. Learn. 2021, 16, 17-28. [CrossRef]

70. Centea, D.; Srinivasan, S. Collaboration with Industry in the Development and Assessment of a PBL Course BT-Visions and Concepts for Education 4.0; Auer, M.E., Centea, D., Eds.; Springer International Publishing: Cham, Switzerland, 2021; pp. 181-188.

71. Bloom, B.S. The 2 Sigma Problem: The Search for Methods of Group Instruction as Effective as One-to-One Tutoring. Educ. Res. 1984, 13, 4-16. [CrossRef]

72. Crouch, C.H.; Mazur, E. Peer Instruction: Ten years of experience and results. Am. J. Phys. 2001, 69, 970-977. [CrossRef]

73. Vaughan, N. Student Engagement and Blended Learning: Making the Assessment Connection. Educ. Sci. 2014, 4, 247-264. [CrossRef]

74. Garrison, D.R.; Kanuka, H. Blended learning: Uncovering its transformative potential in higher education. Internet High. Educ. 2004, 7, 95-105. [CrossRef]

75. Halverson, L.R. Conceptualizing Blended Learning Engagement; ProQuest Dissertations Publishing: Ann Arbor, MI, USA, 2016.

76. McDonald, P.L. Adult Learners and Blended Learning: A Phenomenographic Study of Variation in Adult Learners' Experiences of Blended Learning in Higher Education; The George Washington University: Washington, DC, USA, 2012.

77. Gikandi, J.W.; Morrow, D.; Davis, N.E. Online formative assessment in higher education: A review of the literature. Comput. Educ. 2011, 57, 2333-2351. [CrossRef]

78. Henrie, C.R.; Halverson, L.R.; Graham, C.R. Measuring student engagement in technology-mediated learning: A review. Comput. Educ. 2015, 90, 36-53. [CrossRef] 